\title{
REFLEXIONES EN TORNO A LA AUTONOMÍA DEL DERECHO HUMANO AL MEDIO AMBIENTE ${ }^{1}$
}

Reflections on the autonomy of the human right to the environment

Luis Alberto Rivas Mosquera ${ }^{2}$

Yairan Liceth Mosquera Palacios ${ }^{3}$

Pablo Antonio Mena Mena ${ }^{4}$

\section{RESUMEN.}

El medio ambiente se constituye en una de las fuentes más necesarias para la pervivencia del hombre, pero también en ese eje necesario para la vida de los demás seres vivos que condicionan la vida. No es de oculto conocimiento que históricamente se han venido haciendo esfuerzo para la protección al medio ambiente pero estos han sido puros pañitos de agua tibia, claro ejemplo de ellos nos demuestra las constantes y significativas afectaciones al Medio ambiente en nuestro país y otros países del sistema interamericano de derechos humanos.

Nuestro Departamento del Chocó, como uno de los más biodiversos del Estado colombiano, ha venido sufriendo en carne propia las afectaciones directas al medio ambiente lo que se evidencia en casos como lo ocurrido en el Municipio de Rio Quito, y Unguía, donde se evidencian nocivas afectaciones en nuestro entorno y que de manera clara repercute en la salud humana (mal formaciones en los efectos, contaminación del agua, del aire, erosión del suelo entro otras).

Por ello la presente propuesta gira entonces en la viabilidad de reconocer el medio ambiente como un derecho humano de forma autónoma, esto es que se proteja de manera

\footnotetext{
${ }^{1}$ Artículo científico entorno a la necesidad de entender al Derecho al Medio Ambiente como un Derecho Humano Autónomo. 2 Abogado Titulado de la Facultad de Derecho de la Universidad Tecnológica del chocó "Diego Luis Córdoba", Joven Investigador, miembro de los semilleros de investigación en derecho procesal y de justicia constitucional adscritos al Grupo de Investigación Democracia, Constitución e Instituciones Jurídico Procesales.”, reconocido por Colciencias con código COL019726920190131183, adscrito al Centro de Investigaciones Socio jurídicas SIJUS de la Universidad Tecnológica del Chocó. ORCID ID: https://orcid.org/0000-0002-9558-9895 E-mail: yumil-makial@hotmail.es

3 Abogada de la Facultad de Derecho de la Universidad Tecnológica del chocó "Diego Luis Córdoba". https://orcid.org/00000001-6072-4658 E-mail: yalipamos@hotmail.com

4 Abogado de la Facultad de Derecho de la Universidad Tecnológica del chocó "Diego Luis Córdoba". https://orcid.org/00000003-3494-5953 E-mail: noblemente@hotmail.com
} 
inmediata sin necesidad que para la garantía del mismo se haga para en últimas beneficiar a un individuo de la especie humana.

Palabras clave: Medio ambiente, derecho humano autónomo, medio ambiente, derecho procesal constitucional, control de convencionalidad.

\section{ABSTRACT.}

The environment is one of the most necessary sources for the survival of man, but also in that axis necessary for the life of other living beings that condition life. It is not from hidden knowledge that historically efforts have been made to protect the environment but these have been pure warm water cloths, a clear example of them shows us the constant and significant effects on the environment in our country and other countries of the system Inter-American Commission on Human Rights.

Our Department of Chocó, as one of the most biodiverse of the Colombian State, has suffered from direct affectations to the environment, which is evidenced in cases such as what happened in the Municipality of Rio Quito, and Unguía, where there is evidence of harmful effects. affectations in our environment and that clearly affects human health (bad training in the effects, contamination of water, air, soil erosion among others).

For this reason, the present proposal revolves in the feasibility of recognizing the environment as a human right autonomously, that is to be protected immediately without need for the guarantee of the same is done to ultimately benefit an individual of the human species called person.

Key words: Environment, autonomous human right, environment, constitutional procedural law, conventionality control.

\section{1.) INTRODUCCIÓN}

En los últimos siglos los avances jurídicos ha Estado íntimamente ligados a las luchas de la humanidad por consolidar construcciones más civilizadas sostenibles y duraderas de la vida en sociedad es así como afínales del siglo XVIII y durante XIX (principales revoluciones francesa americana colombiana etc.)El principal avance fue la consolidación de un Estado democrático rompiendo con el paradigma reinante de los imperios y las monarquías hegemónicas

En el silgo XIX se siguió avanzando en la construcción de instituciones solidadas el respeto por el orden jurídico interno y la visión de Estado y nuevamente dos cataclismos de inmensa magnitud (primera y segunda guerra mundial) fueron los que permitieron a la humanidad entrar en una nueva 
dinámica de construcción común de una visión de mundo y no únicamente una visión restringida de la realidad nacional, si no adentrarnos a pensar en la necesidad imperiosa de afrontar las exigencias de un mundo cada vez más globalizado.

Es en este contexto en el que se generan las dinámicas políticas civiles que impulsan la construcción conjunta de estándares internacionales de protección para la humanidad tanto a nivel mundial (sistema universal de protección a los derechos humanos) y a nivel regional (sistema interamericano de protección a los derechos humanos ) la construcción de tratados verbi gracia la convención americana de derechos humanos la carta de la OEA la convención de Sansalvador todos estos con una construcción antropocéntrica.

De este interés internacional por la construcción de estándares de protección y por ende de responsabilidad para los Estados encontramos documentos como la declaración de Estocolmo, la Convención de Rio y otros que propenden por la construcción de unos lineamientos sustantivos entorno a la protección del medio ambiente tema central de nuestro análisis. Sin embargo como lo plantea (Manuel Conrrado paz ) la materialización efectiva de ese corpus iuris ambiental de origen internacional que se ha adoptado en la mayoría de Estados democráticos modernos ha sido un tema más complejo por cuanto el cumplimiento de la normatividad ambiental implica en muchos casos la afectación a intereses macro-económicos que trasladan loa discusión una disyuntiva conservacionista- o extractivita y más en países del tercer mundo donde esta se traduce en protección al medio ambiente vs desarrollo económico.

\section{2.) DERECHO AMBIENTAL: CONCEPTO Y EVOLUCIÓN.}

Antes de iniciar a desglosar la evolución histórica del derecho ambiental se hace necesario precisar el concepto del mismo, para esto nos apoyamos en el doctor Raúl Brañes Ballesteros, quien define el derecho ambiental como el conjunto de normas jurídicas que regulan las conductas humanas que pueden influir de una manera relevante en los procesos de interacción, que tiene lugar entre los sistemas de los organismos vivos y sus sistemas de ambiente, mediante la generación de efectos de los que se espera una modificación significativa de las condiciones de existencia de dichos organismos. (Ballesteros, 2000)

De igual forma, Garetto (2018, p. 175) nos plantea que el derecho ambiental se encuentra en una etapa de plena formación; en las últimas décadas se ha desarrollado como una rama autónoma del derecho administrativo tanto a nivel nacional, como a nivel de la UE y en el plano del derecho internacional.

Luego de definir en debida forma lo que se entiende por derecho ambiental se hace necesario 
precisar su evolución histórica tanto en el ámbito internacional como en el ámbito local.

El territorio para la población afro descendiente, se refiere a todos los derechos: económicos, sociales, culturales y ambientales. En otras palabras, no es la tierra, es el territorio el que adquiere el sentido de espacio simbólico y político de sus identidades; es un medio de vida netamente material. Para el acceso seguro a sus territorios y su posesión tranquila, la Honorable Corte Constitucional (Sentencia T-769/09) se pronunció en favor de la necesidad de que los pueblos indígenas y afro descendientes "den su consentimiento previo, libre e informado y previo de planes de desarrollo o de inversión a gran escala, según sus costumbres y tradiciones" que tengan mayor impacto dentro del territorio de afro descendientes e indígenas. Esta sentencia de la Corte es una herramienta valiosa frente a políticas públicas cuya tendencia es a la concertación de la tierra y al control sobre el territorio por parte de los "foráneos". Territorios que hasta el momento no han sido respetados ni por las autoridades públicas ni por los particulares que aprovechándose de la poca y la mala gestión de algunas entidades aceden a los territorios de estas poblaciones desconociendo parámetros legales particularmente las siguientes disposiciones:

- Constitución Política: Art. 1- Colombia es un Estado social de derecho, es democrática, participativa y pluralista y tiene prevalencia el interés general. Art. 2- Son fines esenciales del Estado; facilitar la participación de todos en las decisiones que los afectan Art. 7- Protección de la diversidad étnica, Art. 8- Obliga al Estado y a las personas proteger las riquezas culturales y naturales de la Nación. Art. 10 - Establece que las lenguas y dialectos de los grupos étnicos son oficiales en sus territorios. Art. 13 - El Estado debe proteger especialmente a aquellas personas que por su condición económica se encuentren en circunstancia de debilidad. Art. 70 - La cultura en sus diversas manifestaciones es fundamento de la nacionalidad. Art. 40-2, Permite diversas formas de participación democrática. Art. 329, Establece los mecanismos para la conformación de las entidades territoriales indígenas, su forma de administración y las características de los resguardos: propiedad colectiva y no enajenable. Art. 7- El Estado reconoce y protege la diversidad étnica y cultural de la Nación colombiana.

- Ley 99 de 1993 Artículo 76º- La explotación de los recursos naturales deberá hacerse sin desmedro de la integridad cultural, social y económica de las comunidades indígenas y de las negras tradicionales de acuerdo con la Ley 70 de 1993 y el artículo 330 de la Constitución Nacional y las decisiones sobre la materia se tomarán, previa consulta a los representantes de tales comunidades.

- Decreto 1320 de 1998, "Por la cual se reglamenta la consulta previa con las comunidades indígenas y negras para la explotación de recursos naturales dentro de su territorio". 
- Directiva Presidencial 1 de 2010, reseña los mecanismos para la aplicación de la Ley 21 de 1991, señala las acciones que requieren la garantía del derecho a la Consulta Previa y establece los mecanismos mediante los cuales procede el proceso de Consulta Previa.

- Decreto 2820 de 2010 Por el cual se reglamenta las licencias ambientales.

- Decreto 2893 de 2011 Estructura del Ministerio del Interior. En cargado de coordinar la realización de los procesos de Consulta Previa.

- Directiva Presidencial 10 de 2013 “Guía para la realización de Consulta Previa a Comunidades Étnicas".

- Decreto 2163 de 2013 "Protocolo Interinstitucional de Consulta Previa.

Para los grupos étnicos la violación de los derechos humanos implica, la vulneración a su historia misma, cultura, identidad, supervivencia como pueblo, la vulneración de sus derechos territoriales y específicos, como el derecho a la consulta previa, libre e informada, el derecho propio, desconocimiento de las formas de gobernanza, implantación de modelos extractivos en territorios ancestrales de las comunidades, megaproyectos en tierras de grupos étnicos, imposición de monocultivos, confinamiento de población, el no acceso a los bienes y servíos. Por otro lado también se toma como violación de los derechos humanos lo establecido en el Estatuto de Roma de la Corte Penal Internacional Naciones Unidas 1998, artículos 6, 7 y 8, referentes al genocidio, crimen de lesa humanidad y de guerra respectivamente.

En general se considera violación a los derechos humanos, aquellos actos que vulneran los amparos y normas contempladas en el derecho interno de los Estados y en los instrumentos internacionales ratificados por estos, a quienes se les señala del no cumplimiento de sus obligaciones de garantizar, proteger y adoptar disposiciones para evitar la vulneración de los derechos de los ciudadanos, así mismo por las infracciones al DIH, por acción u omisión en su deber legal para que las conductas de hechos internacionalmente ilícitos no ocurran.

\subsection{Derecho ambiental en el plano internacional.}

En el sistema interamericano de derechos humanos, el derecho a un medio ambiente sano está consagrado expresamente en el artículo 11 del Protocolo de San Salvador: 1. Toda persona tiene derecho a vivir en un medio ambiente sano y a contar con servicios públicos básicos. 2. Los Estados parte promoverán la protección, preservación y mejoramiento del medio ambiente. Adicionalmente, este derecho también debe considerarse incluido entre los derechos económicos, sociales y culturales protegidos por el artículo 26 de la Convención Americana. El derecho humano a un 
medio ambiente sano es un derecho con connotaciones tanto individuales como colectivas. En su dimensión colectiva, constituye un interés universal, que se debe tanto a las generaciones presentes y futuras; mientras que su vulneración puede tener repercusiones directas o indirectas sobre las personas, en virtud de su dimensión individual y su conexidad con otros derechos, tales como el derecho a la salud, la integridad personal o la vida, entre otros. La degradación del medio ambiente puede causar daños irreparables en los seres humanos, por lo cual un medio ambiente sano es un derecho fundamental para la existencia de la humanidad. Ahora bien, el derecho a un medio ambiente sano como derecho autónomo es distinto al contenido ambiental que surge de la protección de otros derechos, tales como el derecho a la vida o el derecho a la integridad personal. Algunos derechos humanos son más susceptibles que otros a la degradación ambiental. Los derechos especialmente vinculados al medio ambiente se han clasificado en dos grupos: i) los derechos cuyo disfrute es particularmente vulnerable a la degradación del medio ambiente, también identificados como derechos sustantivos (por ejemplo, los derechos a la vida, a la integridad personal, a la salud o a la propiedad), y ii) los derechos cuyo ejercicio respalda una mejor formulación - 3 - de políticas ambientales, también identificados como derechos de procedimiento (tales como derechos a la libertad de expresión y asociación, a la información, a la participación en la toma de decisiones y a un recurso efectivo). En la presente Opinión Consultiva, la Corte se pronunció sobre las obligaciones sustantivas y de procedimiento de los Estados en materia de protección del medio ambiente que surgen del deber de respetar y garantizar los derechos a la vida y a la integridad personal, por ser estos los derechos sobre los cuales Colombia consultó al Tribunal. No obstante, con base en las consideraciones anteriores, este Tribunal resaltó cómo otros múltiples derechos podrían verse afectados por el incumplimiento de las obligaciones ambientales, incluyendo los derechos económicos, sociales, culturales y ambientales protegidos por el Protocolo de San Salvador, la Convención Americana y otros tratados e instrumentos, específicamente, el derecho a un medio ambiente sano.

El derecho ambiental formalmente tuvo nacimiento en 1972 con la declaración de Estocolmo, no obstante en el ámbito internacional con anterioridad aun cuando existía una casi nula conciencia ambiental o al menos así lo fue hasta antes de la década de los 60 y las iniciativas de tutela del medio ambiente eran frágiles y exiguas, en el plano mundial se desarrollaron algunas iniciativas en torno a la defensa del medio ambiente, el primer antecedente data del año1885 ${ }^{5}$, también una de ellas fue la frustrada Convención de Londres de 1900,

La conciencia ambiental entendida como la necesidad del hombre de procurar la tutela del medio ambiente se inició a impulsar en el escenario internacional a comienzo de los años 60 cuando la

${ }^{5}$ A pesar que existe el principio de autodeterminación de los pueblos, existen otras obligaciones internacionales superiores al mismo, como lo son las normas que se deben interpretar a favorabilidad del ser humano. 
humanidad inició a pensar en la importancia de la protección al medio ambiente, influenciados por publicaciones como el libro Primavera Silenciosa (Silent Spring) de Rachel Carson en 1962, el cual documentó los efectos negativos de los plaguicidas sobre las aves y el medio ambiente.

Ya en 1972 con la creciente conciencia ambiental que rondaba la opinión internacional la ONU decide tomar cartas sobre el asunto, forjando así en nacimiento de la declaración de Estocolmo, Dicha declaración fue adoptada en la Conferencia de La ONU Sobre el Medio Humano, esta reconoce la importancia del medio humano natural y artificial para el ejercicio de los derechos humanos fundamentales, así como la necesidad de proteger y mejorar el medio humano como un deseo de los pueblos y un deber de los gobiernos.

Reconociendo el derecho soberano de los Estados para explotar sus propios recursos de acuerdo con su propia política ambiental y señalando el deber que tienen los Estados de garantizar que las actividades que se realicen dentro de su jurisdicción o control no causen daño al medio de otros Estados o zonas fuera de toda jurisdicción la Declaración señala la importancia de velar por la conservación, en beneficio de generaciones presentes y futuras, de los recursos renovables y no renovables de la tierra, Se debe detener la descarga al medio y de manera particular al mar, de sustancias contaminantes que pongan en peligro la salud humana y los ecosistemas, Los Estados deben cooperar en el desarrollo del derecho internacional en relación con la responsabilidad y la indemnización a las víctimas de la contaminación y otros daños ambientales, La Declaración reconoce las especiales necesidades de los países en desarrollo en materia de conservación del medio y desarrollo económico y social, en este sentido establece que se debe promover la asistencia financiera y tecnológica como complemento de los esfuerzos internos de los países en desarrollo, así como procurar que las políticas ambientales estén encaminadas a aumentar el potencial de crecimiento actual y futuro de los países en desarrollo, en este mismo sentido, se señala la importancia de destinar recursos a la conservación del medio con especial consideración de las necesidades de los países en desarrollo. (Ministerio de ambiente, 2002)

Posteriormente en la década de los 80 en la comunidad internacional crece la preocupación por la degradación atmosférica producto de la irresponsable actividad del hombre que generan continuas emisiones de gases nocivos, esta preocupación motiva la creación del Convenio de Viena FIRMADO EL 22 DE MARZO DE 19985 es el primer instrumento internacional que busca proteger la salud de los seres humanos y el medio ambiente, de los efectos adversos resultantes de la modificación de la capa de ozono atmosférica que rodea a la tierra y constituye a su vez el primer esfuerzo concreto de las naciones por enfrentar un problema ambiental mundial antes de que sus efectos pudiesen demostrarse científicamente o que se hiciesen evidentes Las Partes se obligan, 
de conformidad con los medios que dispongan, y en la medida de sus posibilidades a cooperar en la investigación e intercambiar información para mejorar la comprensión de los efectos de las actividades humanas sobre la capa de ozono y de los efectos de la modificación de ésta sobre la salud humana y el medio ambiente, así como a adoptar medidas adecuadas para controlar, limitar, reducir o prevenir las actividades humanas cuando se compruebe que tienen o pueden tener efectos adversos como resultado de la modificación probable de la capa de ozono, Igualmente, las partes se comprometen a desarrollar medidas y procedimientos comunes para ser incluidas en protocolos futuros.

La década de los 90 es de gran importancia para el derecho ambiental pues la comunidad internacional materializa esfuerzos para la tutela del medio ambiente, así el 9 de mayo de 1992 en New York se adoptó la convención marco de las naciones unidas sobre el cambio climático reconoce la preocupación global por las actividades humanas que han modificado las concentraciones naturales de gases de efecto invernadero en la atmósfera, intensificando así el efecto invernadero natural estos cambios implicarían un aumento en la temperatura de la superficie y la atmósfera de la Tierra que pueden acarrear efectos negativos sobre los ecosistemas y la humanidad el objetivo principal de la Convención es lograr la estabilización de las concentraciones de gases de efecto invernadero en la atmósfera a un nivel que impida interferencias peligrosas de las actividades humanas en el sistema climático.

Meses después se gestaría la cumbre de la tierra en rio 92 dando así vida a normatividad que se regiría como piedra angular del derecho ambiental, como lo fueron; la declaración de Rio de Janeiro del 16 de junio la cual se concibe Como un conjunto de principios sin fuerza jurídicamente vinculante, la Declaración busca reafirmar y desarrollar la Declaración de la Conferencia de las Naciones Unidas sobre el Medio Humano (Estocolmo, 1972). Esto con el principal objetivo de alcanzar el desarrollo sostenible, reconociendo el derecho de los seres humanos a una vida saludable y productiva en armonía con la naturaleza, así como el derecho soberano de los Estados para aprovechar sus recursos naturales y haciendo explícita la responsabilidad de los mismos de velar por la conservación del medio ambiente, en el sentido de evitar que las actividades que se realizan bajo su jurisdicción o control causen daño al medio ambiente de otros Estados o en áreas fuera de cualquier jurisdicción nacional En el marco de este objetivo, la Declaración contempla acciones que se deberían adoptar en el ámbito social, económico, cultural, científico, institucional, legal y político también se gestó la el convenio sobre la diversidad biológica el 5 de junio del mismo año, Tomando como punto de partida el reconocimiento de la importancia de la diversidad biológica para la evolución y la vida de la biosfera, así como sus valores ecológicos, económicos, científicos, entre otros y del hecho de que la pérdida de la biodiversidad ha sido el resultado de ciertas 
actividades humanas (Preámbulo), el Convenio Sobre la Diversidad Biológica tiene tres objetivos generales: la conservación de la diversidad biológica, la utilización sostenible de sus componentes y la participación justa y equitativa en los beneficios que se deriven de la utilización de los recursos genéticos, mediante, entre otras cosas, un acceso adecuado a esos recursos, una transferencia apropiada de las tecnologías pertinentes y una financiación apropiada.

Después de la convención de Río, todos los tratados económicos importantes comenzaron a incluir la protección del medio ambiente ${ }^{6}$. La Convención sobre el Cambio Climático merece mención especial ya que, desde 1995, sus firmantes se han reunido cada año en la llamada Conferencia de las Partes (COP). En ese marco, en 1997, se presentó el Protocolo de Kioto que fue el primer acuerdo internacional en establecer obligaciones jurídicamente vinculantes para los países desarrollados, en el 2000, 189 países reunidos en Nueva York adoptaron la Declaración del Milenio, misma que fortaleció la importancia del desarrollo sostenible al reconocer la necesidad de un crecimiento económico sostenible con un enfoque en los pobres y el respeto a los derechos humanos dos años más tarde, en 2002, representantes de 190 países acudieron a la Cumbre Mundial de la ONU sobre el Desarrollo Sostenible, en Johannesburgo, para dar seguimiento a los compromisos de la Cumbre de Río. En esa ocasión, adoptaron la Declaración sobre el Desarrollo Sostenible, centrada en el desarrollo y la erradicación de la pobreza con un enfoque jurídico-económico sobre las “asociaciones público-privadas" Y en 2012, la ONU organizó la tercera Conferencia sobre el Desarrollo Sostenible, conocida como Río + 20, la cual convocó a 192 Estados miembros, empresas del sector privado, ONG y otras organizaciones. El resultado fue un documento El Futuro que Queremos. En las 49 páginas del documento, los Estados renuevan su compromiso al desarrollo sostenible y a la promoción de un futuro sustentable el cual es el esfuerzo de la comunidad internacional más reciente en pro de la tutela del medio ambiente.

\section{2.) Protección al medio ambiente en Colombia.}

La normatividad ambiental no surge en Colombia a partir de la expedición de la Constitución de 1991, pues ya desde 1973 con la expedición de la Ley 23, Colombia adoptó el sistema regulatorio para la prevención y control de la contaminación. Así se inicia a gestar la legislación ambiental nacional, regulando aspectos como niveles de contaminación y manejo de residuos. subsiguientemente el Gobierno Nacional, mediante Decreto 2811 de diciembre 8 de 1974, expidió el Código de los Recursos Naturales Renovables y de Protección al Ambiente, el cual se alza como la primera norma ambiental que regula el manejo de los recursos no renovables cinco años más tarde se estableció la Ley 9 de 1979 sobre medidas sanitarias y el Capítulo II del Título VI -Parte III-

${ }^{6}$ Lastimosamente a pesar de los instrumentos internacionales existentes que protegen al medio ambiente los Estados los han tomado de manera pávida, en razón al desarrollo económico. 
Libro II y el Título III de la Parte II -Libro I- del Decreto 2811 de 1974 (Código de los Recursos Naturales Renovables y de Protección al Ambiente), en cuanto a usos del agua y residuos líquidos, Seguido de esto se introdujo el Decreto 1594 de 1984 El Decreto 1594 de 1984 tratante de la anterior, en 1991 se refundó el Estado colombiano cimentándose en la denominada constitución ecológica, que por su contenido proteccionista del medio ambiente fue objeto de constantes enaltecimientos por los doctrinantes, pero era necesario darle desarrollo a los postulados establecidos en la constitución, por eso se creó la Ley 99 de 1993 Como desarrollo de principios y derechos contenidos en la Constitución Nacional de 1991, respuesta al compromiso internacional adquirido en la Declaración de Río en 1992 y ante la gravedad de la situación medio-ambiental, el Congreso Nacional de Colombia expidió la Ley 99 de por la cual se crea el Ministerio del Medio Ambiente, se reordena el sector público encargado de la gestión y conservación del medio ambiente y los recursos naturales renovables, se organiza el Sistema Nacional Ambiental, SINA, y se dictan otras disposiciones, estos antecedente conforman la base sustantiva del derecho ambiental en Colombia.

\section{3.) Protección al medio ambiente en el derecho comparado}

El Estado de ecuador y el Estado de Bolivia, puesto que en la región de sur América son países pioneros en la tutela reforzada desde el rango constitucional al derecho al medio ambiente

El Estado ecuatoriano en su más reciente carta constitucional del año 2008 establece la protección a la naturaleza, entendiendo a esta no solo como como un medio de subsistencia del hombre, sino también como un ente sujeto de derechos, al cual se le debe garantizar protección por parte del Estado, protección que puede ser exigida por cualquier persona, bien sea natural o jurídica, la constitución ecuatoriana reconoce el derecho al medio ambiente como un derecho fundamental, entendiendo este como esencial para el pleno ejercicio de los derechos del hombre, igualmente esta constitución desarrolla a través de su articulado le otorga de derechos al medio ambiente, a la madre naturaleza o pacha mama, con el reconocimiento de estos derechos en la carta constitucional también se intenta garantizar que al momento del Estado ecuatoriano entablar un modelo de explotación de recursos garantice métodos de desarrollo sostenibles que puedan responder a un debido equilibrio ecológico y un avance racional y respetuoso de la naturaleza, con ello se busca garantizar la exclusión del dañino antropocentrismo que ha propiciado tristes catástrofes naturales en pro de un desarrollo económico y tecnológico de los Estados.

El Estado boliviano también ha sentado un importante y admirable precedente en materia de protección al medio ambiente, incluyendo en su norma suprema del año 2009 la protección al medio ambiente estableciendo este como un derecho inherente a todos los habitantes de este Estado y también dotándolos de herramientas jurídicas para solicitar su tutela en caso de que las autoridades 
competentes no actuaran de manera oficiosa ante afectaciones al medio ambiente, además el Estado boliviano impulsa un pensamiento de tipo ambientalista orientado a garantizar un desarrollo sostenible basado en una explotación racional de los recursos los cuales no comprometan las necesidades de las generaciones futuras, obrando así con cuidado y diligencia debida para evitar desastres ecológicos que puedan afectar además de las generaciones futuras a los habitantes del presente por la destrucción de su medio de habitación, por eso se consagra que todo aquel que realice actividades que ocasionen impacto ambiental debe reparar en debida forma las consecuencias de su actividad para no afectar la armonía ecológica del medio ambiente.

\section{4) El derecho al medio ambiente como un derecho humano desde la perspectiva interna- cional.}

Entendiendo los derechos humanos como derechos inherentes a todos los seres humanos, sin distinción alguna de nacionalidad, lugar de residencia, sexo, origen nacional o étnico, color, religión, lengua, o cualquier otra condición. Todos tenemos los mismos derechos humanos, sin discriminación alguna. Estos derechos son interrelacionados, interdependientes e indivisibles. (unidas) y entendiendo estos como necesarios para la realización de cualquier plan de vida (Carbonell, 31 oct. 2013)la doctrina internacional ha desarrollo la posibilidad de entender el derecho al medio ambiente como un derecho humano, esto motivado en la necesidad de un medio ambiente sano como condición esencial para ejercitar los derechos humanos de manera suficiente, desarrollando así nuestro plan de vida conforme a nuestra voluntad, no obstante la comunidad internacional ha recibido estos planteamientos de manera pávida, pues atendiendo a intereses económicos y posibilidades de desarrollo de los Estados notan incompatible la posibilidad de creación de una norma de carácter internacional que garantice una tutela efectiva del medio ambiente como derecho humano, Los avances más importantes hacia el reconocimiento del Derecho ambiental como un derecho humano han sido elaborados por tribunales internacionales de Derechos Humanos, en su jurisprudencia, con casos como AwasTingni contra Nicaragua, Moiwana contra Suriname, Sawhoyamaxa contra Paraguay, Comunidad indígena Yakye Axa contra Paraguay, Comunidad Indígena Sawhoyamaxa contra Paraguay, Kuna y Emberá de bayano contra Panamá; entre otros han sido casos emblemáticos de tutela ambiental en el sistema interamericano, en el sistema europeo casos como arrondelle contra Reino Unido, López Ostra contra España, Kyrtatos contra Grecia Martínez Martínez contra España y otros más han servido como precedente de protección al medio ambiente en el continente europeo, Otro ejemplo de tutela ambiental y quizá el más claro en normatividad internacional vinculante es la Carta Africana de Derechos Humanos y de los Pueblos que consagra en su artículo 24 que todos los pueblos tendrán derecho a un entorno general satisfactorio favorable a su desarrollo, (CARTA AFRICANA SOBRE LOS DERECHOS HUMANOS Y DE LOS PUEBLOS) en cumplimiento de este articulo la comisión africana en su 
informe de 2001 estableció que las obligaciones correlativas que el artículo impone a los Estados. De este modo, consideró que el derecho al medio ambiente impone obligaciones tanto negativas (deber de abstenerse de actuar de modo que se vulnere este derecho) como positivas (en tanto que debe actuar para garantizar su realización y cumplimiento progresivo) (Decisión de la ACHPR, págs. 52-3).

Las afectaciones al medio ambiente generan graves consecuencias para el ser humano, desde la imposibilidad de generar alimentos, y disfrutar del paisaje, hasta representar una amenaza a la vida por la degradación de los sujetos que habitan las zonas afectadas, el derecho al medio ambiente sano reviste una gran importancia en el desarrollo de los derechos humanos, tutelar el medio ambiente es una obligación del hombre pues como lo indica Hans Jonas el humano es el único ser vivo que tiene responsabilidad, porque pueden elegir alternativas de acción, (Jonas, 1975) y entendiendo esto el debate no debe centrarse a día de hoy únicamente en si debe o no brindársele derechos a la naturaleza como ente autónomo por cuanto día a día nos acercamos a ese punto de inflexión y lo necesario es tomar cartas en el asunto y garantizar la protección del medio ambiente ya sea como ente no humano poseedor de derecho o como medio indispensable para el desarrollo de la vida en condiciones de dignidad

Ahora siendo esto así porque los Estados siguen haciendo caso omiso y no emprenden acciones eficaces en la protección del medio ambiente en la mayoría de los casos porque la protección del medio ambiente y su conservación supone la afectación directa o indirecta e intereses macro económicos que resultan inclinando la balanza en favor del uso irracional de los recursos y la afectación de los derechos de las personas

\section{3) EI reconocimiento del medio ambiente como un derecho humano para su mayor eficacia} dentro de nuestro sistema regional de protección de Derechos Humanos.

Si bien existen algunos países en Suramérica como Ecuador y Bolivia los cuales reconocen a la pacha mama como sujeto de derechos debido a su importancia, en Colombia, aunque la Constitución Política expresamente no lo contempla, si establece algunos artículos para la protección del medio ambiente como se dejó claro con anterioridad e incluso nuestra carta política es llamada la constitución verde. Este tema está tomando mucha importancia, toda vez que el medio ambiente ha venido sufriendo múltiples afectaciones por diferentes factores, bien sea por la deforestación, la contaminación por residuos sólidos de las fuentes hídricas y uno muy importante la contaminación de la fuentes hídricas con mercurio producido por la minería, este factor generó un pronunciamiento de la Corte constitucional con la sentencia C-T 622 de 2016, Magistrado Ponente JORGE IVÁN PALACIO PALACIO, la cual reconoce al Rio Atrato uno de los más importantes del departamento del Chocó cono sujeto de derechos; que lo lleva a poder entender al medio ambiente también como víctima del conflicto armado interno. 


\subsection{El medio ambiente como víctima del conflicto armado en colombiano}

Este conflicto que duro más de 50 años, que ha dejado miles de personas heridas, asesinadas y poblaciones desplazadas, también ha dejado otra víctima como lo es el medio ambiente. Esta víctima del conflicto armado colombiano, en especial en el departamento del Chocó, ha sufrido múltiples afectaciones, por ejemplo; la deforestación causada por los grupos ilegales para poder sembrar cultivos ilícitos, ò al momento de establecer sus campamentos, que además, genera la pérdida del hábitat de la fauna del lugar, de otro lado, la contaminación del aire por los químicos provenientes de los laboratorios que utilizan para la producción de sustancias psicotrópicas, otra afectación es la contaminación de las fuentes hídricas derivadas de la explotación minera con mercurio, que genera afectación a la fauna acuática y a la salud de las personas, toda vez, que muchos utilizan esa agua contaminada para realizar múltiples actividades, bañarse, cocinar entre otras.

Podemos observar de manera contundente que estos efectos del conflicto armado vulneran el derecho constitucional que tenemos todos los colombianos a gozar de un ambiente sano. Artículo 79 de la Constitución Política de Colombia. Este derecho también está consagrado en el artículo 11 \#1 del Protocolo De San Salvador. Colocando en riesgo a las generaciones futuras afectando de manera tajante el concepto de desarrollo sostenible a que se refiere el artículo 3 de la Ley 99 del 93. Donde reza, Se entiende por desarrollo sostenible el que conduzca al desarrollo económico, a la elevación de la calidad de vida y al bienestar social, sin agotar la base de recursos naturales renovables en que se sustenta, ni deteriorar el medio ambiente o el derecho de las generaciones futuras a utilizarlo para la satisfacción de sus propias necesidades.

La directora del Instituto Humboldt BrigitteBaptiste explicó que, "además de víctima, el ambiente fue parte del conflicto por la distribución y acceso inequitativos a los beneficios que ofrece la biodiversidad: "el derecho y la cualidad de controlar procesos ecosistémico y de disputar la gobernabilidad de los territorios fue un elemento central en la historia del conflicto desde el punto de vista ambiental". Instituto Humboldt (2017)

Los Estados deben cooperar para continuar desarrollando el derecho internacional en lo que se refiere a la responsabilidad y a la indemnización a las víctimas de la contaminación y otros daños ambientales que las actividades realizadas dentro de la jurisdicción o bajo el control de tales Estados causen a zonas situadas fuera de su jurisdicción ONU (1972).

\section{Minería ilegal}

El departamento del choco es unos de los más ricos en minerales como el oro y el platino, todo esto debido a su posición geográfica, a su composición hidrográfica y la naturaleza de sus terrenos.

Chocó es uno de los treinta y dos departamentos de Colombia, localizado en el noroeste del país, 
en la región del Pacífico colombiano. Comprende las selvas del Darién y las cuencas de los ríos Atrato y San Juan. Su capital es la ciudad de Quibdó.

Es el único departamento de Colombia con costas en los océanos Pacífico y Atlántico. Es igualmente el único departamento limítrofe con Panamá. Cuenta con una superficie $46.530 \mathrm{Km}^{2}$, lo que representa el $4.07 \%$ del territorio nacional. Su capital es la ciudad de Quibdó y está dividido política y administrativamente en 30 municipios. Según el Dane de 2016, cuanta con una población de 505.016 habitantes.

En general las minas del Chocó y de Barbacoas son consideradas como las más ricas. En la Provincia del Chocó el suelo es, por decirlo así, enteramente de oro. No sólo posee en su superficie las más ricas maderas, se sacan también de su suelo los tesoros más preciosos y más abundantes; por todas partes donde se cava, entre ciento y ochocientas varas de altura, se encuentra oro. (Restrepo, Vicente, 1988)

Una misión del Programa de las Naciones Unidas para el Medio Ambiente (ONU Medio Ambiente) visitó distintas áreas degradadas por el conflicto armado en los departamentos de Chocó y Antioquia. Allí identificó aspectos puntuales en los que se deben concentrar las acciones para la gestión sostenible de los recursos y la conservación del medioambiente en el posconflicto.

De continuar esta actividad sin una estrategia integral, puede llegar a ponerse en riesgo la paz en esos territorios, porque esta actividad ilícita es muy fácil de ser cooptada por grupos al margen de la ley y nuevos actores de la guerra. (Revista semana, 2017).

Esta realidad es tan preocupante, que en un estudio efectuado por el DNP se menciona que Colombia es el tercer país que más libera mercurio en el mundo con 75 toneladas anuales, ubicándose detrás de China e Indonesia. Lo anterior a causa principalmente de la minería de oro artesanal y de pequeña escala. De igual manera, se indica que el $86 \%$ de la minería en el país se realiza sin título minero y sin licencia ambiental, lo que genera graves problemas sociales y una gran tragedia ambiental que, además, según el Instituto Nacional de Salud, ha generado 1.126 casos de intoxicación Rodríguez. (2016).

\section{Deforestación}

Para nadie es un secreto que la deforestación en el departamento del Chocó como en muchos otros departamentos, está muy asociada con el conflicto armado, ya que se talan hectáreas de bosques para dedicarlas al cultivo de coca, dejando de esta forma a muchas especies sin habita y afectando 
el suelo por el monocultivo.

"E1 58 \% de la deforestación en Colombia ha ocurrido en municipios de conflicto. En los últimos 25 años en Colombia se han deforestado 5 millones de hectáreas, de las cuales 3 millones están en municipios de conflicto armado", señaló Simón Gaviria, director del DNP. Al parecer, el cultivo de coca es uno de los factores que más ha contribuido a que se disparen las cifras de tala. Se calcula que por cada hectárea que se siembre de aquella planta, se deben deforestar 1,7 hectáreas de bosque. Y anualmente, como lo muestra el DNP, se siembran unas 74.687 ha de coca en Colombia. (Redacción vivir, 2015).

Aunque los cultivos de coca no son la principal causa de deforestación en Colombia, estos han generado impactos en los ecosistemas, afectando la biodiversidad en áreas de gran importancia ambiental. Según la metodología de la Oficina de las Naciones Unidas contra la Droga y el Delito - UNODC5, la interpretación de imágenes de satélite indica que los cultivos de uso ilícito (coca) en Colombia se localizan en 24 de los 32 departamentos del país entre los que se encuentra el departamento del choco. (Bello, J.C., Báez., M. Gómez, M.F., Orrego, O. y Ñägele, L. (ed), 2014, p. 214)

De acuerdo con la última actualización de cifras de monitoreo de bosques (2016), los principales motores de la deforestación en Colombia son praderización $45 \%$; cultivos de uso ilícito, $22 \%$; desarrollo de infraestructura vial, $10 \%$; incendios forestales, $8 \%$; ganadería extensiva, $8 \%$ extracción ilícita de minerales, $7 \%$.

Durante el 2016 la deforestación se concentró en siete núcleos identificados en el país: Arco de deforestación de la Amazonia con un 34 \%; Pacífico Norte, 14 \%; Nororiente de Antioquia, 8 \%; Norte de Santander, 8 \%; Pacífico Sur, 2\%; Sur del Chocó, 1 \% y Sarare, 1\% de la deforestación observada (Ideam, 2017)

Para el 2016 las zonas más críticas en cuanto a deforestación de las 7 enunciadas hay 2 en el choco Sur del Chocó: en los municipios de Río Quito, El Cantón de San Pablo, Atrato, Cértegui y Unión Panamericana se reporta el $1 \%$ de la deforestación observada, y en el Pacífico norte: en el área del noroccidente antioqueño y el norte de Chocó se concentró el 14 \% de la deforestación reportada. Las áreas afectadas son principalmente los municipios de Turbo (Antioquia); Riosucio y Unguía (Chocó). Revista semana (2017).

Ahora para poder entrar a analizar la necesidad de entender el medio ambiente como un derecho humano autónomo se hace necesario definir dos fenómenos de gran importancia para nuestros fines Primero el de la internacionalización del derecho constitucional y el segundo el de la constitucionalización del 
derecho internacional que según Quinche Ramírez puede definirse de la siguiente manera:

"La internacionalización del derecho constitucional consiste en el proceso de inclusión del Derecho Internacional dentro del derecho constitucional interno de un país, de modo tal que las normas internacionales ocupen un lugar definido dentro del sistema de fuentes del respectivo Estado. La constitucionalización del Derecho Internacional consiste en un proceso distinto, en virtud del cual, se acepta que los tratados sobre derechos humanos tienen una dimensión constitucional, es decir, que son constituciones del orden internacional, que implican la supremacía y respeto de los derechos humanos." (Quinche, 2009,p.169)

Estos Fenómenos resultan de trascendental importancia por cuanto han permitido una dinámica interacción entre el ordenamiento interno y las normas internacionales facilitando así la construcción y consolidación del control de convencionalidad y la generación de nuevas tesis ${ }^{7}$ que buscan facilitar la efectiva implementación del sistema interamericano para garantizar la promoción y protección de los derechos humanos

En este contexto tal y como lo indica el maestro Bazán (2014) la suscripción de un tratado internacional en materia de derechos humanos arroja una obligación positiva y una negativa es decir una obligación de hacer y una de no hacer las de hacer tendientes a generar las condiciones que permitan las garantías para la protección a los derechos humanos y las de no hacer que consiste en abstenerse de realizar actuaciones que limiten de manera injustificada el goce de los derechos humanos consagrados en el tratado o convenio internacional

Por lo tanto cuando un Estado miembro del sistema deja de aplicar el control de convencionalidad difuso (Ferrer Mac-Gregor 2011) correspondiente a la hora de tomar las determinaciones judiciales o actuaciones administrativas ${ }^{8}$ que involucren el goce de derechos humanos está desconociendo la obligación que imponen los artículos 1.1 y 2 de la convención americana y por ende podría ser encontrado responsable internacionalmente

Siendo así resulta preocupante la decidía de algunos Estados con respecto a la protección a los derechos humanos de sus ciudadanos haciendo un breve recuento de la jurisprudencia interamericana en materia de protección del derecho al medio ambiente encontramos que la corte ha desarrollado su jurisprudencia entorno a la protección al medio ambiente en casos como AwasTingni c. Nicaragua, Moiwana c. Suriname, Caso Comunidad indígena Yakye Axa c. Paraguay el caso de la Comunidad Indígena Sawhoyamaxa c. Paraguay Saramaka c. Surinam XákmokKásek c. Paraguay Sarayaku c.

\footnotetext{
${ }^{7}$ La jurisprudencia de la Corte Interamericana ha reconocido al Medio Ambiente como eje fundante en diario vivir del ser humano. ${ }^{8}$ Caso Almonacid Arellano y otros vs. Chile" -26/sep/2006.
} 
Ecuador Kuna y Emberá c. Panamá Pueblos Kuna de Madungandí y Emberá de Bayano c. Panamá, todos por afectaciones al territorio de comunidades indígenas y degradación en su calidad de vida, desconociendo su estrecha relación con el medio ambiente, esto con el fin de obtener un desarrollo económico por parte del Estado, el único caso que aun cuando trató de una problemática originada en torno a explotación de recursos naturales no tuvo ocurrencia en territorio de sujetos étnicos fue el caso Claude Reyes y otros Vs. Chile Impulsado por la negativa del Estado chileno a suministrarle información concerniente a un proyecto de industrialización forestal, lo que conllevó a acudir a instancias internacionales, cabe resaltar que en los anteriores casos es llamativa la ocurrencia de afectaciones similares en otros Estados partes, aun cuando la corte en el caso AwasTingni vs. Nicaragua el primero de estos ${ }^{9}$ este caso sentó un precedente de cumplimiento obligatorio para todos los Estados que aceptan la competencia contenciosa de la corte interamericana de derechos humanos como lo ha establecido la corte en su propia jurisprudencia, la ocurrencia de violaciones en otros Estados guardando aspectos facticos similares es un motivo de preocupación, y ante esto es menester intentar vislumbrar luces de alguna herramienta jurídica que permita la real y efectiva protección de los derechos de las comunidades considerando a demás lo tardío de las causas ante el sistema interamericano de derechos humanos.

Por todo esto partiendo del esquema de equivalentes funcionales de Niklas Luhmann que si bien nace en la sociología ha sido aplicada en el derecho ${ }^{10}$ según Arriaga Alvares en esta teoría no es el sistema o la estructura lo que se sostiene con funciones o procedimientos si no la funcionalidad lo que antecede al sistema y por ende los equivalentes funcionales pueden procurar ofrecer soluciones funcionales a un mismo problema (Arriaga,2013).

\section{Medio ambiente como sujeto de derechos}

Existen algunos países en Suramérica como ecuador y Bolivia los cuales reconocen a la pacha mama como sujeto de derechos debido a su importancia, en Colombia, aunque la Constitución Política expresamente no lo contempla, si establece algunos artículos para la protección del medio ambiente. Este tema está tomando mucha relevancia, toda vez que el medio ambiente ha venido sufriendo múltiples afectaciones por diferentes factores, bien sea por la deforestación, la contaminación por residuos sólidos de las fuentes hídricas y uno muy importante la contaminación de la fuentes hídricas con mercurio producido por la minería, este factor generó un pronunciamiento de la corte constitucional con la sentencia C-T 622 de 2016 la cual reconoce al rio Atrato uno de los más importantes del departamento del Chocó cono sujeto de derechos.

\section{El Medio Ambiente y su Protección en el Sistema Interamericano de Derecho Humanos}

Si bien en el sistema interamericano de protección de derechos humanos, y el universal no existe

\footnotetext{
${ }^{9}$ Instrumentos Internacionales.
} 
un compendio o un corpus iuris que determine o defina de manera expresa el medio ambiente como un derecho humano autónomo, o independiente ya que la protección que se le da a este es a través de los individuos de la especie humana o personas, si debemos decir que existen instrumentos itos en materia de protección a los derechos humanos y al derecho internacional humanitario que han hecho referencia a nuestro entorno natural, lo mismo ha hecho la jurisprudencia de Órganos Supra Constitucionales, Cortes Internas y el la doctrina internacional, una referencia es la Declaración Universidad de Derechos Humanos que data de 1948 en donde una de las ideas primarias era ofrecerle al hombre una tierra llena de libertades pero también de garantías que le permitieran gozar de un medio propicio para el desarrollo de cada uno de sus derechos y libertades. Paralelo a ello ya en 1972 se desarrolla la Convención de Estocolmo, de donde se resaltan los principios que, aunque de manera enunciativa proclamaban la importancia y necesidad de que los Estados del Planeta tierra adoptaran medidas para proteger la especie humana y su medio ambiente como componente que condicionaba su existir., nuestro Estado Colombiano sin ser ajeno a dicha realidad adopto dicho principios y los introdujo a nuestro canon constitucional dándole la relevancia y categoría de derechos fundamental constitucional al medio ambiente fundamentos que se cimentan en el artículo 79 constitucional entre otras disposiciones normativas entre las que resaltamos: La Ley 23 de 1973, mediante la cual Colombia adoptó el sistema regulatorio para la prevención y control de la contaminación. Así se inicia a gestar la legislación ambiental nacional, regulando aspectos como niveles de contaminación y manejo de residuos. subsiguientemente el Gobierno Nacional, mediante Decreto 2811 de diciembre 8 de 1974, expidió el Código de los Recursos Naturales Renovables y de Protección al Ambiente, el cual se alza como la primera norma ambiental que regula el manejo de los recursos no renovables cinco años más tarde se estableció la Ley 9 de 1979 sobre medidas sanitarias y el Capítulo II del Título VI -Parte III- Libro II y el Título III de la Parte II -Libro I- del Decreto 2811 de 1974 (Código de los Recursos Naturales Renovables y de Protección al Ambiente), en cuanto a usos del agua y residuos líquidos, Seguido de esto se introdujo el Decreto 1594 de 1984 El Decreto 1594 de 1984 tratante de la anterior, en 1991 se refundó el Estado colombiano cimentándose en la denominada constitución ecológica, que por su contenido proteccionista del medio ambiente fue objeto de constantes enaltecimientos por los doctrinantes, pero era necesario darle desarrollo a los postulados establecidos en la constitución, por eso se creó la Ley 99 de 1993 Como desarrollo de principios y derechos contenidos en la Constitución Nacional de 1991, respuesta al compromiso internacional adquirido en la Declaración de Río en 1992 y ante la gravedad de la situación medio-ambiental, el Congreso Nacional de Colombia expidió la Ley 99 de por la cual se crea el Ministerio del Medio Ambiente, se reordena el sector público encargado de la gestión y conservación del medio ambiente y los recursos naturales renovables, se organiza el Sistema Nacional Ambiental, SINA, y se dictan otras disposiciones, estos antecedente conforman la base sustantiva del derecho ambiental en Colombia..

La década de los 90 es de gran importancia para el derecho ambiental pues la comunidad internacional 
materializa esfuerzos para la tutela del medio ambiente, así el 9 de mayo de 1992 en New York se adoptó la convención marco de las naciones unidas sobre el cambio climático reconoce la preocupación global por las actividades humanas que han modificado las concentraciones naturales de gases de efecto invernadero en la atmósfera, intensificando así el efecto invernadero natural estos cambios implicarían un aumento en la temperatura de la superficie y la atmósfera de la Tierra que pueden acarrear efectos negativos sobre los ecosistemas y la humanidad el objetivo principal de la Convención es lograr la estabilización de las concentraciones de gases de efecto invernadero en la atmósfera a un nivel que impida interferencias peligrosas de las actividades humanas en el sistema climático.

Meses después se gestaría la cumbre de la tierra en rio 92 dando así vida a normatividad que se regiría como piedra angular del derecho ambiental, como lo fueron; la declaración de rio de janeiro del 16 de junio la cual se concibe Como un conjunto de principios sin fuerza jurídicamente vinculante, la Declaración busca reafirmar y desarrollar la Declaración de la Conferencia de las Naciones Unidas sobre el Medio Humano (Estocolmo, 1972). Esto con el principal objetivo de alcanzar el desarrollo sostenible, reconociendo el derecho de los seres humanos a una vida saludable y productiva en armonía con la naturaleza, así como el derecho soberano de los Estados para aprovechar sus recursos naturales y haciendo explícita la responsabilidad de los mismos de velar por la conservación del medio ambiente, en el sentido de evitar que las actividades que se realizan bajo su jurisdicción o control causen daño al medio ambiente de otros Estados o en áreas fuera de cualquier jurisdicción nacional En el marco de este objetivo, la Declaración contempla acciones que se deberían adoptar en el ámbito social, económico, cultural, científico, institucional, legal y político también se gestó la el convenio sobre la diversidad biológica el 5 de junio del mismo año, Tomando como punto de partida el reconocimiento de la importancia de la diversidad biológica para la evolución y la vida de la biosfera, así como sus valores ecológicos, económicos, científicos, entre otros y del hecho de que la pérdida de la biodiversidad ha sido el resultado de ciertas actividades humanas (Preámbulo), el Convenio Sobre la Diversidad Biológica tiene tres objetivos generales: la conservación de la diversidad biológica, la utilización sostenible de sus componentes y la participación justa y equitativa en los beneficios que se deriven de la utilización de los recursos genéticos, mediante, entre otras cosas, un acceso adecuado a esos recursos, una transferencia apropiada de las tecnologías pertinentes y una financiación apropiada.

Después de la convención de Río, todos los tratados económicos importantes comenzaron a incluir la protección del medio ambiente. La Convención sobre el Cambio Climático merece mención especial ya que, desde 1995, sus firmantes se han reunido cada año en la llamada Conferencia de las Partes (COP). En ese marco, en 1997, se presentó el Protocolo de Kioto que fue el primer acuerdo 
internacional en establecer obligaciones jurídicamente vinculantes para los países desarrollados, en el 2000, 189 países reunidos en Nueva York adoptaron la Declaración del Milenio, misma que fortaleció la importancia del desarrollo sostenible al reconocer la necesidad de un crecimiento económico sostenible con un enfoque en los pobres y el respeto a los derechos humanos dos años más tarde, en 2002, representantes de 190 países acudieron a la Cumbre Mundial de la ONU sobre el Desarrollo Sostenible, en Johannesburgo, para dar seguimiento a los compromisos de la Cumbre de Río. En esa ocasión, adoptaron la Declaración sobre el Desarrollo Sostenible, centrada en el desarrollo y la erradicación de la pobreza con un enfoque jurídico-económico sobre las "asociaciones público-privadas" Y en 2012, la ONU organizó la tercera Conferencia sobre el Desarrollo Sostenible, conocida como Río + 20, la cual convocó a 192 Estados miembros, empresas del sector privado, ONG y otras organizaciones. El resultado fue un documento El Futuro que Queremos. En las 49 páginas del documento, los Estados renuevan su compromiso al desarrollo sostenible y a la promoción de un futuro sustentable el cual es el esfuerzo de la comunidad internacional más reciente en pro de la tutela del medio ambiente.

No podemos dejar del lado que los tratados de ginebra de 1949, 1969 junto con sus protocolos adicionales I y II, también aunaron grandes esfuerzos para proteger nuestro ambiente sano, lo anterior porque determinaron bases para los procesos de humanización de las guerras, control en la utilización de las armas bélicas y/o químicas que al impactar causante graves afectaciones a la salud humana y deterioro al medio ambiente.

Sin embargo, estos instrumentos que han propendido por la diversidad e integridad de nuestro entorno natural, han sido tomados como afirma Manuel de Jesús Conrado Paz, de manera pávida ya que con la necesidad de sub desarrollo atienden cuestiones de represión a sus Estados vecinos ponen en una balanza entre la protección al medio ambiente y su cuestión desarrollo como potencias del mundo y entrar a un grupo que se puede distinguirse con la letra $\mathrm{G}$, y terminan es por la necesidad de desarrollarse dejando a nuestro entorno en segundo plano.

\section{Deber del Estado Colombiano de Reparar al Medio Ambiente como víctima en el Marco de la Justicia Transicional.}

En el momento histórico que vive el Estado Colombiano, por su transición del conflicto armado sin precedentes en el mundo por su duración por más de 60 años, extensión golpeo todos los sectores de la sociedad y por su degradación en el tiempo. Por lo anterior y teniendo en cuenta que la madre naturaleza es sujeto de derecho en tal sentido víctima del conflicto armado colombiano ya sea por acción o por omisión se ha permitido que la misma sufriera y sigue padeciendo en carne propia constantes afectaciones, en tal sentido en el rubro presupuestal nacional con apoyo o 
cooperación, inspección y vigilancia de organizaciones internacionales destinar a la reaparición al medio ambiente como víctima con miras a establecer políticas públicas efectivas de prevención, conservación, mantenimiento y restauración del ecosistema colombiano, para asegurar la diversidad e integridad de los mismos bajo los principios justicia, equidad y desarrollo sostenible.

\section{Responsabilidad.}

El deber del Estado Colombiano de reparar al medio ambiente como víctima del conflicto armado interno, se sustenta en el artículo 90 de la Constitución Política Colombiana el cual obliga al Estado a responder patrimonialmente por los daños antijurídicos que le sean imputables, causados por la acción o la omisión de las autoridades públicas; y que el evento de ser condenado el Estado a la reparación patrimonial de uno de tales daños, que haya sido consecuencia de la conducta dolosa o gravemente culposa de un agente suyo, aquél deberá repetir contra éste, esto último es lo que conocemos como acción de repetición.

La responsabilidad antes descrita se explica porque en muchos casos con conflicto armado que ha padecido el Estado Colombiano las autoridades han conocido de su posible ocurrencia y no han hecho nada, un caso emblemático fueron las constantes denuncias que realizo la Diócesis de Quibdó, sobre la presencia de diversos grupos armados en las zonas del bajo Atrato y las autoridades competentes nunca hicieron nada para evitar dichos enfrentamientos dejando al azar la ocurrencia de la masacre de Bojayá y la de la cuenca del rio Cacarica, donde como se explicó con anterioridad el medio ambiente sufrió significativas afectaciones.

\section{CONTROL DE CONVENCIONALIDAD}

En la actualidad ha ganado bastante relevancia jurídica el concepto de control de convencionalidad figura jurídica que tiene habían según la Corte Interamericana y la doctrina internacional garantizar la garantía de los derechos humanos, toda vez que a través de ella se verifica que ninguna norma de orden interna le sea contrario a la normas de raigambre convencional, lo anterior nos lleva a entender que las leyes, decretos incluso las Constituciones interna de los Estados están obligadas a estar en consonancia con la norma convencional.

La Corte Interamericana de derechos Humanos, es consciente que los jueces y tribunales internos están sujetos al imperio de la ley y, por ello, están obligados a aplicar las disposiciones vigentes en el ordenamiento jurídico. Pero cuando un Estado ha ratificado un tratado internacional como la Convención Americana, sus jueces, como parte del aparato del Estado, también están sometidos a ella, lo que les obliga a velar porque los efectos de las disposiciones de la Convención no se vean mermadas por la aplicación de leyes contrarias a su objeto y fin, y que desde un inicio carecen de efectos jurídicos. 
Desde el caso Almonacid Arellano vs. Chile, como primer antecedente de esta figura jurídica, la Corte IDH ha ido precisando el contenido y alcance del concepto de control de convencionalidad en su jurisprudencia, para llegar a un concepto complejo que comprende los siguientes elementos:

a) Consiste en verificar la compatibilidad de las normas y demás prácticas internas con la $\mathrm{CADH}$, la jurisprudencia de la Corte IDH y los demás tratados interamericanos de los cuales el Estado sea parte; b) Es una obligación que corresponde a toda autoridad pública en el ámbito de sus competencias; c) Para efectos de determinar la compatibilidad con la $\mathrm{CADH}$, no sólo se debe tomar en consideración el tratado, sino que también la jurisprudencia de la Corte IDH y los demás tratados interamericanos de los cuales el Estado sea parte; d) Es un control que debe ser realizado ex officio por toda autoridad pública; y e) Su ejecución puede implicar la supresión de normas contrarias a la $\mathrm{CADH}$ o bien su interpretación conforme a la $\mathrm{CADH}$, dependiendo de las facultades de cada autoridad pública.

El control de convencionalidad se ejerce entre las normas del derecho interno y la CADH, toda vez que vincula al juez y a los demás funcionarios de los países suscriptores del Pacto de San José en la tarea de limitar el poder político y defender los derechos humanos. La Corte Interamericana ideó este mecanismo judicial para garantizar la $\mathrm{CADH}$.

El control de convencionalidad ha probado ser un instrumento útil para la realización de los derechos humanos y la consolidación de la democracia. El sometimiento de los jueces al imperio de la ley y al derecho interno no obsta entonces para desconocer el mandato de la CADH cuando el Estado la ratifica. Los jueces deben atender la interpretación oficial de la CADH por parte de la jurisprudencia de la Corte, la cual ha jugado un papel significativo en los procesos de transición de la dictadura a la democracia, o de conflicto armado interno a la suscripción de acuerdos de paz. Pocos países latinoamericanos han estado libres de este destino.

Desde lo anterior se vislumbra que esta figura jurídica es de gran importancia no solo en la transición de dictaduras a democracias, sino que su alcance también se extiende a la protección constante de los derechos humanos, de ello se parte que el Control de convencionalidad será la gran herramienta de este modelo de justicia étnica con enfoqué diferencia sino que también nos proporcionara seguridad jurídica acerca de la protección de los derechos humanos tanto en el presente como en tiempos ulteriores, esto nos permite que las legislaciones en materia de reparaciones integrales a las víctimas del conflicto armado estén en consonancia con los estándares y parámetros internacionales, siendo estos proteccionista y proclama de la seguridad jurídica, igualdad, confianza legítima de las personas naturales de un determinado Estado cuando en cualquier cede solicite la reclamación y efectiva reparación integral a los mismos desde una perspectiva o panorama especial. 
La Corte Interamericana de derechos Humanos, es consciente que los jueces y tribunales internos están sujetos al imperio de la ley y, por ello, están obligados a aplicar las disposiciones vigentes en el ordenamiento jurídico. Pero cuando un Estado ha ratificado un tratado internacional como la Convención Americana, sus jueces, como parte del aparato del Estado, también están sometidos a ella, lo que les obliga a velar porque los efectos de las disposiciones de la Convención no se vean mermadas por la aplicación de leyes contrarias a su objeto y fin, y que desde un inicio carecen de efectos jurídicos.

En palabras de la Corte:

“...los jueces y tribunales internos están sujetos al imperio de la ley y, por ello, están obligados a aplicar las disposiciones vigentes en el ordenamiento jurídico. Pero cuando un Estado ha ratificado un tratado internacional como la Convención Americana, sus jueces, como parte del aparato del Estado, también están sometidos a ella, lo que les obliga a velar porque (sic) los efectos de las disposiciones de la Convención no se vean mermadas por la aplicación de leyes contrarias a su objeto y fin, y que desde un inicio carecen de efectos jurídicos. En otras palabras, el Poder Judicial debe ejercer una especie de "control de convencionalidad" entre las normas jurídicas internas que aplican en los casos concretos y la Convención Americana sobre Derechos Humanos. En esta tarea, el Poder Judicial debe tener en cuenta no solamente el tratado, sino también la interpretación que del mismo ha hecho la Corte Interamericana, intérprete última de la Convención Americana ${ }^{11}$ ".

\section{RESPONSABILIDAD DE LOS ESTADOS A LA LUZ DEL DERECHO INTERNACIO- NAL PÚBLICO.}

En materia de responsabilidad de los Estados y la reparación por las obligaciones contraídas por estos en los tratados y demás instrumentos de derecho internacional de protección de los derechos humanos, encontramos en el ámbito universal diferentes herramientas jurídicas que incorporan la responsabilidad y la obligación de los Estados a reparar, por hechos ilícitos internacionalmente considerados, entre estos, las violaciones a los derechos humanos, entre los que se incluyen todos aquellos que se desprenden del conflicto armado, indicando además que sus víctimas tienen derecho a la verdad, justicia, reparación y garantías de no repetición. Uno de estos instrumentos es la Resolución 1503 de 1970 de la Organización de Naciones Unidas -ONU, que nos enmarca la obligación respecto a la protección de los derechos; la Asamblea General de las Naciones Unidas, deliberó sobre la responsabilidad internacional del Estado por hechos Ilícitos (AG/56/83), señalando la obligación de reparar, especialmente en su artículo $31^{12}$ :

\footnotetext{
${ }^{10}$ Corte Constitucional. Sentencia C 225 de 1995 (M.P. Alejandro Martínez Caballero: mayo 18 de 1995).

Posición reiterada en sentencia C-578 de 1995 (M.P. Eduardo Cifuentes Muñoz: diciembre 4 de 1995), sentencia C-358/97. (M.P. Eduardo Cifuentes Muñoz: agosto 5 de 1997), sentencia C-191-98 (M.P. Eduardo Cifuentes Muñoz: mayo 6 de 1998).

${ }^{11}$ 1) El Estado responsable está obligado a reparar íntegramente el perjuicio causado por el hecho internacionalmente ilícito. 2) El perjuicio comprende todo daño, tanto material como moral, causado por el hecho internacionalmente ilícito del Estado.
} 
De igual forma, la Resolución 60/147, aprobada por la Asamblea General el 16 de diciembre de 2005, incorporó los principios y directrices básicos sobre el derecho de las víctimas de violaciones manifiestas de las normas internacionales de derechos humanos y de violaciones graves del derecho internacional humanitario a interponer recursos y obtener reparaciones.

Además, el Estado es responsable por un hecho ilícito de derecho internacional cuando se presentan varias circunstancias: a) acción, acto u omisión atribuible al Estado es decir, por un órgano agente, representante suyo- propios hechos o en unidad con terceros, cause daño antijurídico, afectación o vulneración de derechos, b) acción, acto u omisión que constituya una violación o se encuentre tipificado como tal en el derecho internacional ${ }^{13}$. Todo esto trae consigo la obligación de reparar por el hecho ilícito, afectación, vulneración de los derechos e igualmente el deber de suspender las acciones, hechos o abstenerse de realizar, y en su defecto adoptar medidas para que cese el acto tipificado como violatorio del derecho internacional o la vulneración de los derechos humanos.

\section{EN CUANTO A LA OPINIÓN CONSULTIVA OC-23/17 DE 15 DE NOVIEMBRE DE 2017 SOLICITADA POR LA REPÚBLICA DE COLOMBIA, LA CORTE INTERAMERICANA DE DERECHOS HUMANOS, EXPRESO LO SIGUIENTE:}

a. Los Estados Partes de la Convención Americana tienen la obligación de respetar y garantizar los derechos consagrados en dicho instrumento a toda persona bajo su jurisdicción.

b. El ejercicio de la jurisdicción por parte de un Estado acarrea su responsabilidad por las conductas que le sean atribuibles y que se aleguen violatorias de los derechos consagrados en la Convención Americana.

c. La jurisdicción de los Estados, en cuanto a protección de los derechos humanos de las personas bajo la Convención Americana, no se limita a su espacio territorial. El término jurisdicción en la Convención Americana es más extenso que el territorio de un Estado e incluye situaciones más allá de sus límites territoriales. Los Estados están obligados a respetar y garantizar los derechos humanos de todas las personas bajo su jurisdicción, aunque no estén dentro de su territorio.

d. El ejercicio de la jurisdicción bajo el artículo 1.1 de la Convención Americana, fuera del territorio de un Estado, es una situación excepcional que debe analizarse en cada caso concreto y de manera restrictiva.

e. El concepto de jurisdicción bajo el artículo 1.1 de la Convención Americana abarca toda situación en la que un Estado ejerza autoridad o control efectivo sobre la o las personas, sea dentro o fuera de su territorio. f. Los Estados deben velar porque su territorio no sea utilizado de modo que se pueda causar un daño significativo al medio ambiente de otros Estados o de zonas fuera de los

\footnotetext{
${ }^{12}$ http://www.corteidh.or.cr/docs/opiniones/resumen_seriea_23_esp.pdf
} 
límites de su territorio. Por tanto, los Estados tienen la obligación de evitar causar daños transfronterizos.

g. Los Estados están obligados a adoptar todas las medidas necesarias para evitar que las actividades desarrolladas en su territorio o bajo su control afecten los derechos de las personas dentro o fuera de su territorio. h. Frente a daños transfronterizos, una persona está bajo la jurisdicción del Estado de origen si media una relación de causalidad entre el hecho que ocurrió en su territorio y la afectación de los derechos humanos de personas fuera de su territorio. El ejercicio de la jurisdicción surge cuando el Estado de origen ejerce un control efectivo sobre las actividades llevadas a cabo que causaron el daño y consecuente violación de derechos humanos.

\section{4.) CONCLUSIONES}

La declaratoria o reconocimiento del Derecho al medio ambiente como un derecho autónomo, se convierte en la herramienta más eficaz a la hora de proteger este importante sistema compuesto de organismos vivos y que condicionan la vida del individuo dentro del universo. Es necesario no solo que los Estados de manera individual reconozcan al medio ambiente como sujeto de derechos constitucionales en el plano interno, si no que los esfuerzo se cristalice de mejor manera desde toda la comunidad internacional en aras de crear un Ius Comunes Interamericano, tenga por finalidad reconocer y proteger los derechos no solo de la persona humana, sino que también de entender que el ser humano sin medio ambiente no es nada.

Por último, y como lo manifiesta Viguri \& Marullo (2016):

A nuestro juicio es indispensable un replanteamiento en el tema de la defensa de los derechos de la persona, plasmados en nuestro trabajo básicamente en cuanto a su vida y salud, junto a la protección del medio ambiente. Solamente una buena política ambiental en el marco de las empresas contribuirá a alcanzar el objetivo de proteger la salud de las personas y velar por la defensa del medio ambiente. Invertir en eco-innovación y nuevas tecnologías, medir el impacto ecológico de sus actividades y transmitir a inversores y clientes información medioambiental en sus informes anuales son las soluciones que se deben adoptar. (p. 108-109)

\section{REFERENCIAS BIBLIOGRÁFICAS.}

Corte Constitucional de Colombia; M.P Humberto Sierra Porto; 2006; Sentencia c-028.

Constitución Política de Colombia de 1991.

Honorable Corte Constitucional (Sentencia T-406 de 1992 M.P. CIRO ENGARITA VARÓN)

Convención Americana de Derechos Humanos. 
CIDH. Cfr. Caso Myrna Mack Chang Vs. Guatemala. Fondo, Reparaciones y Costas. Sentencia de 25 de noviembre de 2003. Serie C No. 101.

Declaración de Estocolmo de 1972.

Garetto, Roberto (2018). El Principio del Desarrollo Sostenible en el contexto de la Unión Europea y en el plano internacional. Revista Jurídica Mario Alario D’Filippo, Vol. X Nº. 20, pág. 173 - 186. DOI: https://doi.org/10.32997/2256-2796-vol.10-num.20-2018-2154

Sentencia C 225 de 1995 (M.P. Alejandro Martínez Caballero: mayo 18 de 1995)

Sentencia C-358/97. M.P. Eduardo Cifuentes Muñoz.

Velandia Canosa, E. (2015).Derecho Procesal Constitucional. http:/www.corteidh.or.cr/docs/ opiniones/resumen_seriea_23_esp.pdf

Viguri Perea, Agustín; Marullo, Maria Chiara (2016). El derecho a un medio ambiente sano y la encrucijada de los alimentos transgénicos. Revista Jurídica Mario Alario D’Filippo, VIII (15), pág 100-111. DOI: https://doi.org/10.32997/2256-2796-vol.8-num.15-2016-1526 